\title{
PSYCHOLOGICAL INTERVENTION IMPACT IN PATIENTS UNDERGOING DIALYSIS' MENTAL HEALTH - CASE STUDY
}

\author{
Rezalda Shehi $^{{ }^{*}, \text { Sabina Tahsini }}{ }^{1}$, Arjana Strakosha ${ }^{2}$, Ariel Como ${ }^{2}$ \\ ${ }^{1}$ Hygeia Hospital Tirana, Albania; \\ ${ }^{2}$ University Hospital Centre "Mother Theresa" Tirana, Albania;
}

*Correspondent Author Rezalda Shehi, e-mail: rezaldashehi@gmail.com;

Received December 2019; Accepted January 2020; Published March 2020;

DOI: https://doi.org/10.31407/ijees10.209

\begin{abstract}
Chronic kidney disease includes conditions that damage the kidneys and decrease patients' ability to keep healthy. In many cases those patients remains the choc of their life, a trauma. Their quality of life will never be the same and it is difficult for them to invest in other interests. They are often unsatisfied, angry, fatalists and depressive. The aim of the psychology unit was to help them to invest again desires and wishes, in order to increase their quality of life. Helping them to connect their thoughts, emotions and behaviors would bring them in a new psychosomatic state and help them to improve the quality of life. Case presentation: A 36-years old man is undergoing dialysis in Hygeia Hospital. For the first time he was admitted on 2004, stayed for one year and a half in dialysis and went through the transplant. He returned in 2018. Because of his young age and the return after the transplant, it was very difficult for him to cope and accept the disease. He had difficulties to express his anger, worries. CORE-OM test, a psychological instrument that is validated in Albania and evaluate the overall mental wellbeing was passed. The scale of Problems/psychological problems resulted symptomatic our hypothesis was that there is always a possibility for the psychologist to intervene with patients with chronic kidney disease, because psychic organizations are in constant evolution. The psychological intervention helped him to increase quality of life, get back to a normal life, and extend his interests and social network.
\end{abstract}

Key words: quality of life, hemodialysis, depression, psychological intervention 